\title{
Neuromodulation for Chronic Daily Headache
}

\author{
Gianluca Coppola ${ }^{1}$ (D) Delphine Magis ${ }^{2} \cdot$ Francesco Casillo $^{1} \cdot$ Gabriele Sebastianelli $^{1} \cdot$ Chiara Abagnale $^{1}$. \\ Ettore Cioffi ${ }^{1}$. Davide Di Lenola ${ }^{1}$. Cherubino Di Lorenzo ${ }^{1}$. Mariano Serrao ${ }^{1}$
}

Accepted: 24 January 2022 / Published online: 7 February 2022

(c) The Author(s) 2022

\begin{abstract}
Purpose of Review We reviewed the literature that explored the use of central and peripheral neuromodulation techniques for chronic daily headache (CDH) treatment.

Recent Findings Although the more invasive deep brain stimulation (DBS) is effective in chronic cluster headache $(\mathrm{CCH})$, it should be reserved for extremely difficult-to-treat patients. Percutaneous occipital nerve stimulation has shown similar efficacy to DBS and is less risky in both $\mathrm{CCH}$ and chronic migraine (CM). Non-invasive transcutaneous vagus nerve stimulation is a promising add-on treatment for $\mathrm{CCH}$ but not for $\mathrm{CM}$. Transcutaneous external trigeminal nerve stimulation may be effective in treating CM; however, it has not yet been tested for cluster headache. Transcranial magnetic and electric stimulations have promising preventive effects against $\mathrm{CM}$ and $\mathrm{CCH}$.

Summary Although the precise mode of action of non-invasive neuromodulation techniques remains largely unknown and there is a paucity of controlled trials, they should be preferred to more invasive techniques for treating $\mathrm{CDH}$.
\end{abstract}

Keywords Deep brain stimulation $\cdot$ Sphenopalatine ganglia $\cdot$ Occipital nerve $\cdot$ Vagus nerve $\cdot$ Trigeminal nerve $\cdot$ Transcranial magnetic stimulation $\cdot$ Direct current stimulation

\section{Introduction}

Despite numerous therapeutic advances in recent years, there are several unfulfilled needs in the acute and prophylactic care of primary headaches. Attack therapies are ineffective in one in four patients [1], have numerous side effects and contraindications, and can cause a transformation from episodic to chronic daily headache $(\mathrm{CDH})[2]$. On the other hand, preventive therapies are ineffective in approximately $50 \%$ of patients, have frequent and intolerable side effects, and numerous contraindications [3, 4], leading to poor patient compliance, with more than half of the patients stopping treatment after 2 months. In a

This article is part of the Topical Collection on Chronic Daily Headache

Gianluca Coppola

gianluca.coppola@uniroma1.it

1 Department of Medico-Surgical Sciences and Biotechnologies, Sapienza University of Rome Polo Pontino, Latina, Italy

2 Headache and Pain Multimodal Treatment Centre (CMTCD), Department of Neurology, Neuromodulation Centre, CHR East Belgium, Verviers, Belgium recent study of more than 8500 patients suffering from chronic migraine, persistence in oral preventive treatment was $25 \%$ at 6 months and $14 \%$ at 12 months, with a similar trend even after the second or third prescription [3]. This unsatisfactory picture is further complicated in patients with CDHs, where prophylactic treatment is ineffective in 9 out of 10 patients, many of whom become drug-resistant [3]. Moreover, less than $60 \%$ of patients are willing to take any of the drugs available, even if they could benefit from them [5]. Although the situation has improved, it has not yet been completely resolved with the advent of monoclonal antibodies against calcitonin gene-related peptide, the molecule, or its receptor, where the therapeutic response is in line with the 'old' prophylactic therapies; however, the adverse events are much less, which means that there is better adherence to treatment [6].

For all these reasons, numerous non-pharmacological approaches that are invasive and risky, such as deep brain stimulation, stimulation of the great occipital nerve, and transcutaneous electrical stimulation, have been attempted during the last decades.

In this review, we will explore studies that have used noninvasive and invasive neuromodulation techniques for the purpose of non-pharmacological treatment of $\mathrm{CDHs}$, such as chronic migraine $(\mathrm{CM})$ and chronic cluster headache $(\mathrm{CCH})$. 


\section{Non-invasive Neuromodulatory Techniques}

\section{Transcranial Magnetic Stimulation}

The rationale for the use of TMS in migraine derives from human studies and studies on animal models, where a single pulse of TMS is able to interrupt the cortical spreading depression, the electrocortical phenomenon at the base of the migraine aura [7]. Human studies have shown how repetitive (r)TMS can bring back within normal limits the altered cortical responsiveness that is frequently detected in migraineurs during the pain-free period [8-10] (Fig. 1).

After three open studies reported the effectiveness of single-pulse (s)TMS in relieving pain, reducing the pain intensity of a single attack [11], sTMS was tested and found to be effective as prophylaxis therapy when used for several days in patients with episodic and CM, with or without medication overuse $[12,13]$. In a unique multicentre, single-arm, open-label study, Starling et al. reported the effectiveness of four sTMS pulses delivered twice daily over the occipital area in patients with episodic (90\%) and chronic (10\%) migraine who were allowed to continue their prophylaxis during the study. They reported a significant reduction in the number of days with headache/ month $(-2.75)$ compared to the baseline, a $>50 \%$ reduction in headache days in $46 \%$ of patients, a reduction in acute medication days and HIT-6 impact questionnaire, and difference from baseline in total headache days of any pain intensity (mild, moderate, or severe) [13].

Repetitive TMS has been tested as a preventive treatment for both episodic and chronic migraine (Table 1). Several open and sham-controlled studies [14-20], but not all [21-23], have shown that high-frequency rTMS delivered to the motor cortex or dorsolateral-prefrontal cortex are both able to reduce the frequency of migraine attacks or monthly headache days. In some of these studies, the scales of anxiety, depression [20,24], headache-related disability [15, $16,18,19]$, and subjective perception of headache intensity $[15-18,24]$ also improved after treatment. The limitation of these studies is the inclusion of a heterogeneous group of patients affected by both episodic and chronic forms, often already on prophylaxis and symptomatic drug abuse. In a comparative study, chronic migraine patients treated with high-frequency rTMS obtained a clinical benefit comparable to that obtained with botulinum toxin injection in the first 2 monthly follow-up visits, but not in the third month, so there was a lack of sustained efficacy [18]. We are aware of only one study using high-frequency rTMS to treat, in an openlabel fashion, a group of 19 cluster headache $(\mathrm{CH})$ patients. It reported a beneficial effect of rTMS on the intensity of
Fig. 1 Schematic representation of the sites of possible neuromodulatory intervention in chronic daily headaches. A Transcranial magnetic stimulation on the scalp, B direct current stimulation on the scalp, $\mathbf{C}$ transcutaneous stimulation of the supraorbital branch of the trigeminal nerve, D transcutaneous stimulation of the vagus nerve at the neck, E percutaneous stimulation of the great occipital nerve, and $\mathbf{F}$ deep brain stimulation of the posteroinferior hypothalamus or ventral tegmentum (Created with BioRender.com)

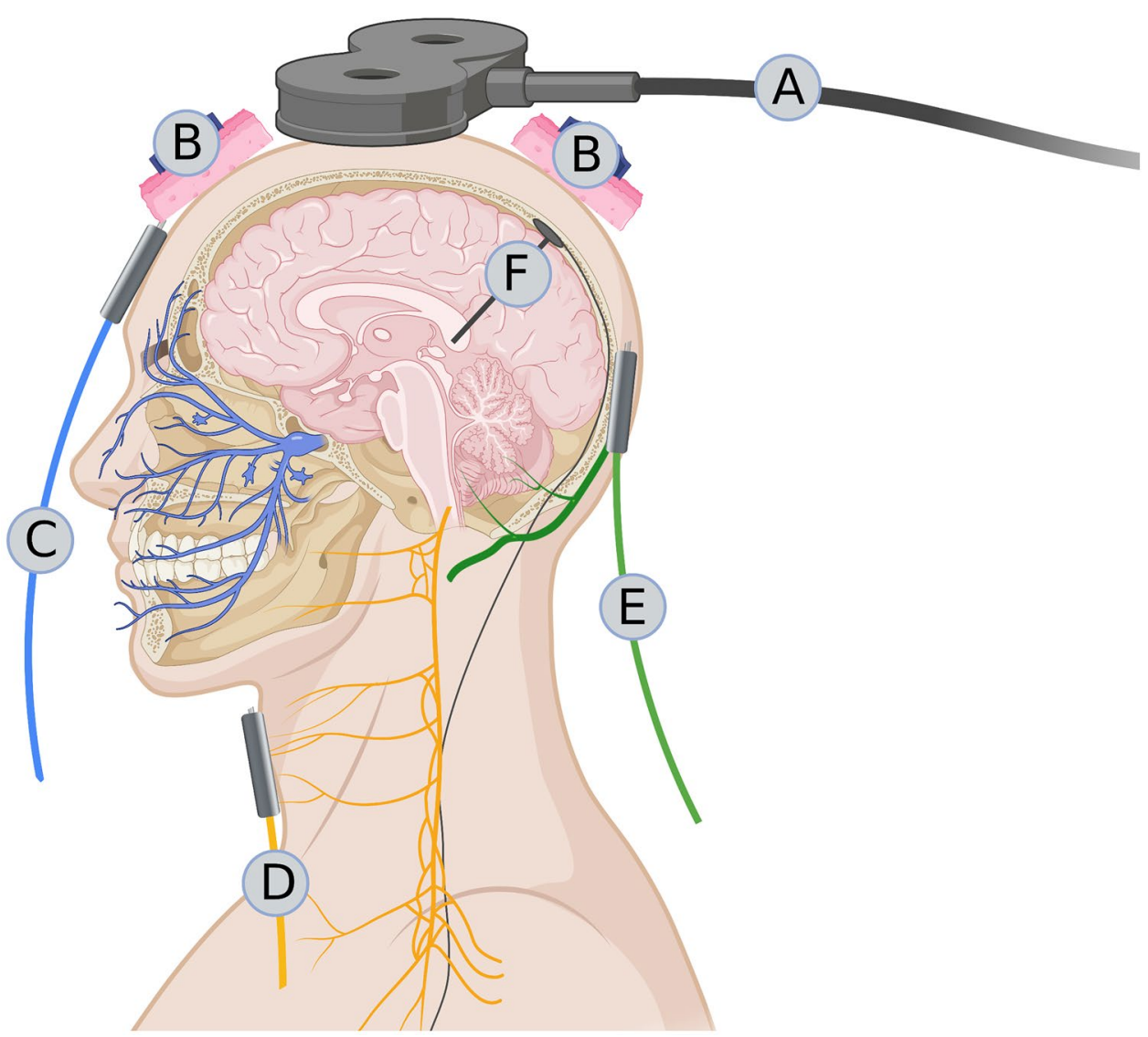




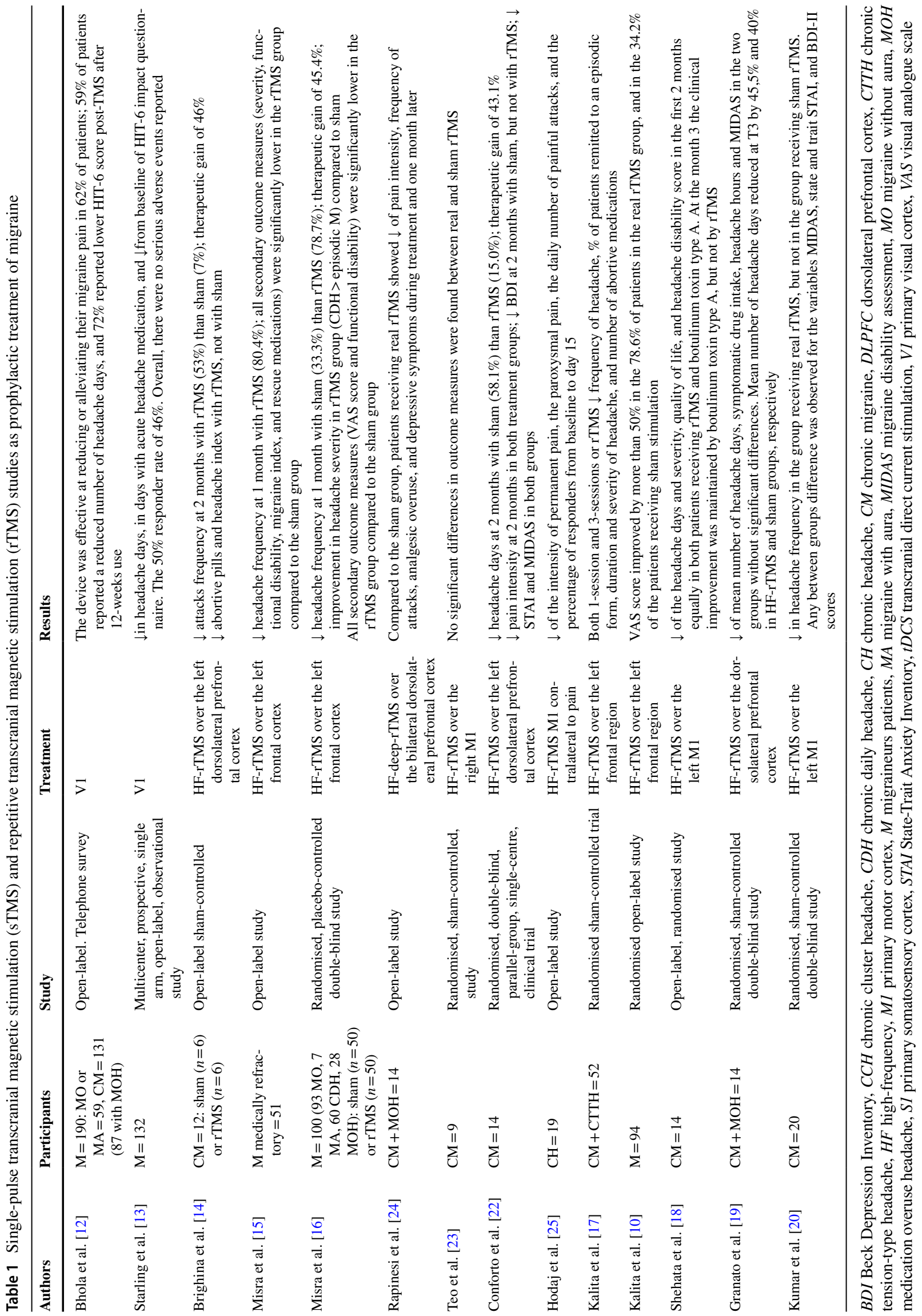


pain, the number of daily attacks, and the percentage of responders up to 15 days after the intervention [25]. Unfortunately, the authors did not specify whether the headache of these patients was episodic or chronic.

Despite the promising results, further controlled trials, including a larger and more selected population of patients, are needed to confirm the real benefits of this non-pharmacological treatment. These studies will benefit from the technological advances provided by neuronavigation [20] and the development of more specific magnetic stimulation paradigms [26].

\section{Transcranial Direct Current Stimulation}

Unlike TMS, tDCS is better tolerated, more portable, less expensive, and easy to use. It has the same capabilities as TMS to modulate brain activity in the opposite way, depending on the polarity of the direct current. It also offers several additional advantages, such as the ability to influence larger cortical areas, being unfocused, the inability to induce action potentials, and the production of fewer physiological artefacts than TMS.

There is a lot of evidence supporting the use of tDCS in the treatment of migraine prophylaxis and $\mathrm{CH}$. First, tDCS has the ability to normalise cortical hyper-responsiveness that is commonly detected in migraine during the intercritical period [27-29]. Second, tDCS can modulate the functional connectivity of cortico-striatal and thalamo-cortical circuits [30]; the former is involved in the chronicity of migraine and the propensity to overuse symptomatic medication [31], and the latter is involved in the recurrence of migraine attacks, as well as in the generation of the symptoms associated with it [32-34]. Moreover, tDCS can modify the strength of restingstate functional connectivity in cortical networks [35] previously involved in migraine pathophysiology [36].

When applied over the visual area, repeated daily sessions of cathodal tDCS (with the anode over the vertex), which enhances cortical excitability, did change migraine-related clinical variables in two randomised sham-controlled trials, including a mixed group of episodic and CM patients [37, 38].

Four small studies using anodal tDCS over the primary motor cortex reported favourable outcomes in both episodic and chronic migraine patients [39-42]. In one study performed in a mixed group composed of episodic and CM patients, Rahimi et al. [43] obtained a favourable outcome using repetitive cathodal stimulation over either the M1 or the $\mathrm{S} 1$ cortex. In a recent study, cathodal stimulation positioned both over V1 (with the anode over the supraorbital region) and over the dorsolateral prefrontal cortex (anode contralaterally) was effective as an add-on treatment during the withdrawal program from medication overuse in a small group of patients with CM [44]. In contrast, in a large multicentre, double-blind, placebo-controlled trial with a 1-year open-label study, Grazzi et al. [45] did not rule out a beneficial clinical effect of anodal or cathodal tDCS over the right M1 in both CM and medication overuse headache patients. Because tDCS applied for 10 continuous days was able to increase the metabolism of the subgenual anterior cingulate cortex [46], an area previously involved in chronic drug-resistant $\mathrm{CH}(\mathrm{rCCH})$ response to treatment with implanted occipital nerve stimulation [47], Magis et al. investigated the therapeutic efficacy of tDCS in patients with rCCH [48••]. In this open-label proof-of-concept study, researchers tested the therapeutic response to anodal tDCS over the frontal area in $\mathrm{rCCH}$, arguing that it would activate the functionally interconnected subgenual anterior cingulate cortex. They observed that excitatory tDCS delivered daily for 4 weeks induced a 37\% drop in weekly attacks frequency and a $50 \%$ responder rate of $43 \%$, which is a promising result, especially considering the difficulty associated with treating such patients $[48 \bullet \bullet]$.

Overall (Table 2), these promising results using classic tDCS suggest that more refined non-invasive stimulation techniques, such as transcranial alternating current stimulation, can be used to modify the abnormal oscillatory neuronal activity that characterises both CM [34] and CCH [49].

\section{Transcutaneous Peripheral Cranial and Extracranial Nerve Stimulation}

The following two non-invasive transcutaneous peripheral stimulation devices have been tested for the treatment of chronic headaches: the external trigeminal neurostimulation (eTN, Cefaly $\left({ }^{\circledR}\right)$ and the external vagus nerve stimulator (eVN, gammaCore $\left.{ }^{\circledR}\right)$.

\section{External Trigeminal Neurostimulation}

Experimental evidence suggests that the mechanism of action of eTN is both peripheral, through segmental "gate control" mechanisms, and central, through suprasegmental mechanisms. The eTN is able to reduce the area under the curve of the blink reflex and to reduce the amplitude of the cortical response to a caloric stimulus sent to the forehead but not to the wrist [50]. This suggests that eTN has a predominantly homotopic action, modulating nociception through a segmental trigeminal-specific mechanism or modulation of the suprasegmental pathway. eTN also seems to induce central effects, such as an increase in reaction time, fatigue, and the critical threshold in the flicker fusion test [51]. Three months of eTN treatment normalised the hypometabolism observed on fluorodeoxyglucose-positron emission tomography [52] and the BOLD hyper signal on functional magnetic resonance imaging [53] of the anterior cingulate gyrus in patients with episodic migraine. In addition, thalamo-cortical somatosensory activity also increased transiently after a single session of eTN stimulation [54]. 


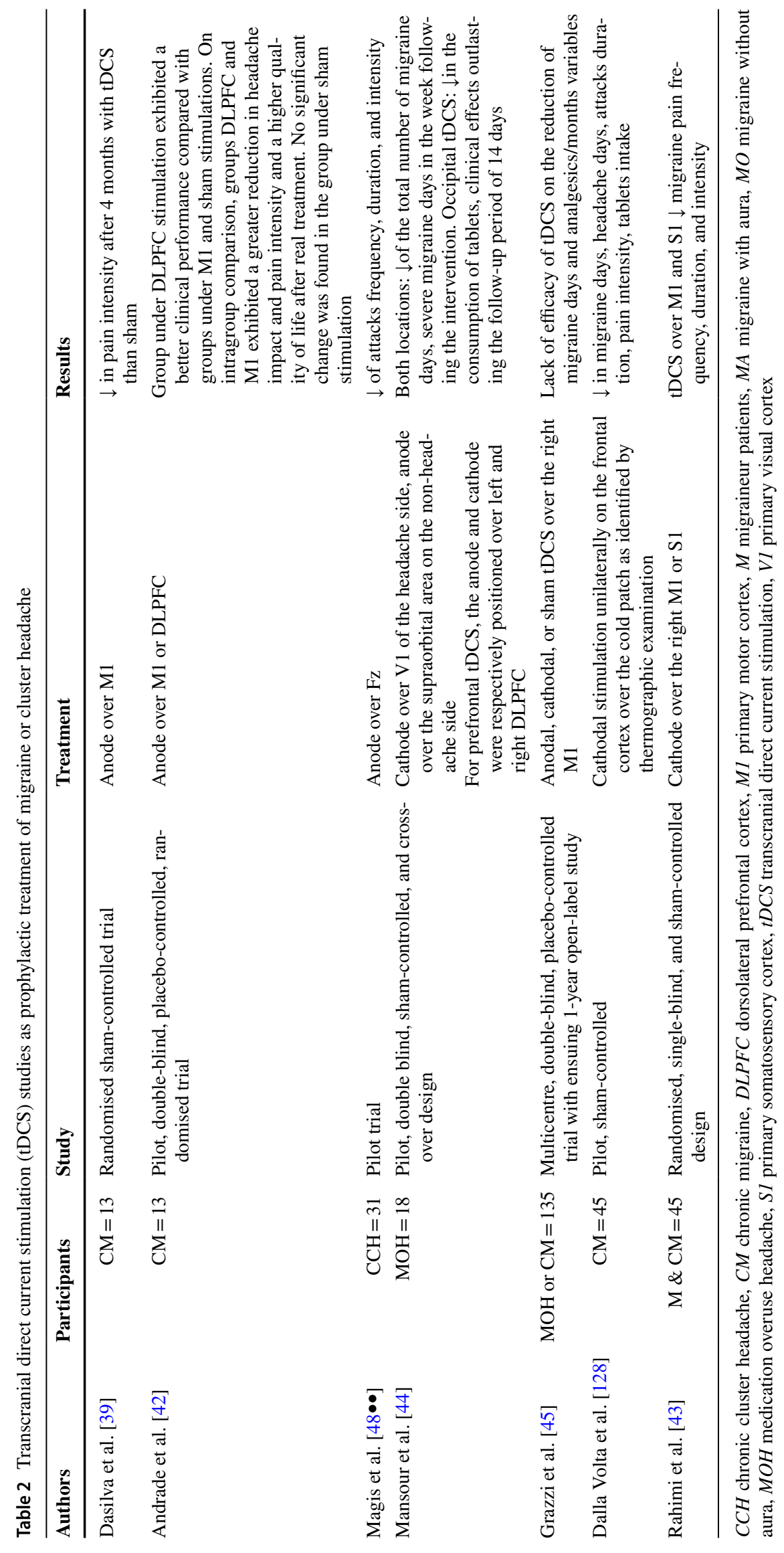


The clinical efficacy of eTN was initially tested in a randomised double-blind sham-controlled trial (PREMICE study) in which a group of patients with episodic migraine achieved a $50 \%$ response rate of $38.2 \%$ in the verum group versus $12.1 \%$ in the sham group. Patients reported no serious adverse events, and the compliance rate was $61 \%$ for the verum group and $54 \%$ for the sham group [55]. Later, eTN was tested in an open-label setting in 58 patients with $\mathrm{CM}$, with and without symptomatic drug abuse and with and without continuous headache, who underwent 1-2 daily 20-min sessions for 3 months, achieving an encouraging $50 \%$ responder rate of $18.97 \%$. When the authors divided the patient group into those with non-continuous headaches and those with continuous headaches, the former had a response rate of $29.41 \%$ and the latter $4.17 \%$ [56]. In another study, Vikelis et al. treated a group of episodic or chronic migraineurs with unsuccessful topiramate treatment. Twenty-seven patients in the initial 35 completed the 3-month treatment with eTN, 23 were satisfied with the transcutaneous stimulator, and the mean number of headache days decreased from 8.9 to $6.3 /$ month, similar to the episodic and chronic forms [57•]. A more recent study also showed a non-significant difference in primary and secondary outcome comparisons between episodic $(N=60)$ and chronic $(N=23)$ migraine at 8 and 12 weeks of treatment with eTN [58].

\section{External Vagus Nerve Stimulator}

The interest in vagus nerve stimulation in the treatment of headaches stems from the evidence of efficacy in the treatment of another accessory brain disorder, epilepsy, when refractory to common treatments. As with eTN, eVN has also aroused interest in headaches due to the miniaturisation process of the devices and the evidence that vagal afferents can be activated transcutaneously [59, 60]. Supporting its use in the treatment of headaches is evidence that $\mathrm{eVN}$ can inhibit cortical spreading depression [61, 62], has antiinflammatory properties, can inhibit trigeminal nociception [63-65], enhance central descending modulation of pain [66], and modulate the activity of the hypothalamus, trigeminal spinal nucleus, pontine nuclei, parahippocampal gyrus, and visual cortex [59]; nonetheless, it inhibits the cranial trigeminal autonomic reflex [67-69]. With the introduction of the GammaCore ${ }^{\circledR}$ device, a portable stimulator of the cervical branch of the vagus nerve, several studies have attempted to prevent both migraine and $\mathrm{CH}$ attacks. In the EVENT trial, Silberstein et al. [70] enrolled 30 patients with $\mathrm{CM}$ who were self-treated with eVN $(120 \mathrm{~s} \times 2$ on the right side of the cervical vagus nerve, 5-10 min apart, 3 times a day for 2 months) and 29 patients using a sham device. After 2 months of treatment, the verum device was well-tolerated and safe; however, it brought about no significant improvement over the sham device in terms of both primary and secondary outcomes. During the open-label phase, 16 patients who had received verum continued to self-administer stimulation for a further 6 months and reported a reduction of 3.6 days with headache/ month at month 8 of treatment. Eleven patients who switched from sham to verum saw a reduction in 2.5 headache days/ month at month 6 of treatment. In another small trial, 26 patients with migraine, 7 of them with chronic migraine, applied eVN bilaterally for $12 \mathrm{~s}$ twice daily or sham for 2 months without any significant improvement, except for a reduction in the number of most severe attacks/month [71]. Other authors tested the effects of bilateral stimulation with eVN (120 s twice daily) for 12 weeks in a mixed group of episodic and CM patients who did not respond to at least four therapeutic classes of prophylaxis. Episodic and CM patients equally reported a $50 \%$ reduction in the pain intensity of headaches, -5.8 headache days/month and -2.8 migraine attacks/month [72]. In a real-world study, 23 patients with CM were self-treated for $90 \mathrm{~s}$ bilaterally, three times a day for three months. Unfortunately, only two patients reported a reduction of at least $30 \%$ in the number of headache days per month [73•].

Overall, we can deduce that stimulation with $\mathrm{eVN}$, although possibly beneficial in a subgroup of $\mathrm{CM}$ patients in some measures, is well-tolerated and safe, has a low magnitude of effect, and is rarely significant in comparison with sham.

$\mathrm{eVN}$ has also been used in the treatment of $\mathrm{CH}$, initially to treat acute attacks in patients with episodic $\mathrm{CH}$ and as a preventive treatment for $\mathrm{CCH}$. A controlled study included 92 patients with $\mathrm{CCH}, 48$ of whom received verum and standard of care, and 49 received only the standard of care [74]. At the end of the 4-week randomisation period, those receiving verum had a significantly greater reduction in the number of attacks per week than the control group (with a treatment gain of 3.9 fewer attacks/week) and a higher 50\% responder rate ( $40 \%$ vs. $8.3 \%$ ). In addition, the verum group showed a $57 \%$ reduction in the frequency of acute drug use. These beneficial effects observed in the group that initially received verum were also maintained during the open-label extension phase, while only slight improvements were observed in those who initially received only standard of care. The patients did not report any serious adverse events related to treatment.

In a retrospective study, Marin et al. [75] analysed data from $29 \mathrm{CCH}$ patients who received eVN funding from the UK National Health Service. After an observation period of 3-6 months, they found that the frequency of attacks decreased from 26.6 to 9.5 attacks/week, and the same decrease was observed for the mean duration and severity of the attacks and the number of acute medications taken with no adverse events.

In a more recent meta-analysis that analysed a pooled population of $225 \mathrm{CH}$ patients (112 episodic and 113 chronic) of whom 108 had received eVN and 117 sham, the $\mathrm{eVN}$ was superior in providing improvement at $15 \mathrm{~min}$ of the 
first treated attack compared to the sham only in the episodic group but not in the chronic group [76].

In summary, in $\mathrm{CCH}, \mathrm{eVN}$ is a promising add-on preventive treatment; however, its efficacy against acute attacks has not been proven.

\section{Invasive Neuromodulatory Techniques}

\section{Deep Brain Stimulation}

DBS was the first neuromodulatory technique to be proposed for the treatment of drug-resistant $\mathrm{CCH}$. Unlike other non-invasive techniques and stimulation of the great occipital nerve, this technique has not been applied for migraine treatment. The rationale for the use of this invasive technique lies in the neuroimaging evidence of the involvement of the posterior inferior hypothalamus in the initiation and maintenance of a $\mathrm{CH}$ attack [77]. It is still debated whether the therapeutic effect observed after months is due to the neuromodulatory effect of areas other than the hypothalamus, but closely connected with it, such as those belonging to the pain neuromatrix $[78,79]$, the descending cortical pain control system [80], and the midbrain tegmentum [81, 82].

According to recent comprehensive reviews [83, 84], 69 patients with drug-resistant $\mathrm{CCH}, 3$ with short-lasting unilateral neuralgiform headache attacks with conjunctival injection and tearing (SUNCT), 1 with paroxysmal hemicrania, and 1 patient suffering from both $\mathrm{CH}$ and SUNCT have been treated with DBS of the posterior-inferior hypothalamus to date in the literature. Of the 73 chronic trigeminal autonomic cephalalgias (TACs), after a mean follow-up of 2.2 years, $31.8 \%$ were pain-free and $34.2 \%$ had an improvement of at least $50 \%$; therefore, the total treatment success rate was $66 \%$ [83]. Only one double-blind randomised controlled trial investigating the efficacy of DBS in patients with $\mathrm{CCH}$ is available in the literature [85]. Unfortunately, probably due to the short observation period of one month in this study, the switched-on stimulator did not induce a significant reduction in attacks compared to the switched-off stimulator. The therapeutic efficacy of DBS is long-term. In fact, in another case series, a group of $17 \mathrm{CCH}$ patients was followed up for up to 8.7 years, observing an improvement in $70 \%$ of patients [86]. DBS takes weeks to show any effectiveness, cannot treat an ongoing attack [87], does not appear to be effective in those who experience attacks on both sides of the head, and attacks may relapse on each interruption during the first years of stimulation [86]. Three patients with drug-resistant SUNCT [88-90] and one patient with paroxysmal hemicrania [91] also benefited from DBS treatment of the posterior-inferior hypothalamus after at least 1 year of stimulation.
According to a review of stimulation coordinates of DBS studies of the posterior hypothalamus observing the involvement of the ventral tegmental area [81, 82], some authors implanted a DBS device in this region in patients suffering from CCH [92-94] and SUNCT [95, 96] and found a reduction in the frequency, severity, and duration of attacks after a median observation period of 18 months in $\mathrm{CCH}$ and 29 months in SUNCT. In parallel, quality of life, mood, anxiety, and novelty-seeking scales improved without changing the cognitive function [92-94].

DBS of both the posterior hypothalamus and the ventral tegmental area is effective in the long term for the treatment of $\mathrm{CCH}$ and other TACs, even though the only available sham-controlled study reported contrary findings. Because of its possible serious side effects, this intracranial invasive treatment should only be recommended in cases of failure of the extracranial invasive neurostimulation methods [97].

\section{Sphenopalatine Ganglion Stimulator}

The activation of the parasympathetic system during $\mathrm{CH}$ attacks and other TACs and their relief after various procedures acting on the sphenopalatine ganglion (SPG) is well known [98]. For these reasons, a randomised controlled trial tested the efficacy of a microstimulator surgically implanted in the posterior wall of the maxillary bone in the pterygopalatine fossa to stimulate the SPG (Pulsante $囚)$. It was initially engineered to treat acute $\mathrm{CH}$ attacks by transcutaneously activating the stimulator via a remote controller. In the pathway CH-I trial, 28 patients with $\mathrm{CCH}$ completed the experimental period, $68 \%$ of whom were responders and $25 \%$ of whom responded only to acute treatment, $7 \%$ responded to both the acute attack and reducing the attack frequency, and $36 \%$ of patients responded only to reducing the attack frequency [99]. At the 1-year follow-up appointment, $45 \%$ of patients continued to respond to acute treatment of attacks (23\% for very severe attacks), while $35 \%$ of the initial $36 \%$ continued to respond with a reduction in attack frequency, suggesting that the daily use of the SPG stimulator may have a prophylactic effect on attacks [100]. In a larger cohort of 88 patients with $\mathrm{CCH}$ in a 12-month open-label prospective study, $55 \%$ of chronic patients were frequent responders, and $74 \%$ of chronic patients were able to stop, reduce, or remain off all preventives [101].

To summarise, although the SPG stimulator is only indicated in the treatment of acute attacks, one or two daily 15-min stimulations outside the usual attacks could be used as a preventive treatment.

\section{Occipital Nerve Stimulator}

ONS finds its rationale in the modulation of the trigeminocervical complex [102]. It consists of continuous electrical stimulation of the great occipital nerve through a 
subcutaneous electrode, which induces paraesthesia in its innervation territory.

Several uncontrolled open-label trials have successfully implanted the ONS in patients with drug-resistant $\mathrm{CCH}$ [47, 103-114]. The literature shows that a total of 262 patients with $\mathrm{CCH}$ were treated and followed up for an average of 39.1 months. These 262 patients had a clinical improvement of at least $50 \%$, with an overall response rate of $66 \%$ (Table 3 ).

ONS was found to be an effective treatment in other chronic headache disorders, such as chronic migraine [104, 115], hemicrania continua [116, 117], paroxysmal hemicrania [118], and SUNCT/short-lasting unilateral neuralgiform headache with autonomic symptoms (SUNA) [118-120].

In an open-label prospective cohort study, Miller et al. identified the presence of pain over the occipital area and severe mood disorders at the time of implantation as strongly associated with poor outcomes in ONS, while a prior response to great occipital nerve block was associated with positive clinical outcomes. Nonetheless, their data showed that patients with SUNCT are better responders than patients with CM [121•].

In a unique international, multicentre, randomised, doubleblind, phase 3, electrical dose-controlled clinical trial, 131 patients with drug-resistant $\mathrm{CCH}$ underwent 24 weeks of ONS at either $100 \%(N=65$, verum) or $30 \%(N=66$, sham) of the individually determined range between paraesthesia threshold and near discomfort [122••]. At the end of the randomisation phase, both groups achieved a $50 \%$ response rate in $44.6 \%$ of the cases. At the end of the following open phase (at week 50), the group that received verum saw their response rate increase to $50 \%$, while the sham group continued to have a rate of $44.6 \%$. The authors concluded that although at first glance the similar results obtained with the two dosages of

Table 3 List of open-label trials implanting percutaneous great occipital nerve stimulator in drug-resistant chronic cluster headache. The mean follow-up period of all patients was weighted by the patient number in individual studies. Taking all trials together, a 50\% clinical improvement can be observed in $66 \%$ of patients

\begin{tabular}{llll}
\hline Authors & $\begin{array}{l}\text { Number of } \\
\text { patients }\end{array}$ & $\begin{array}{l}\text { Follow-up } \\
\text { (months) }\end{array}$ & $\begin{array}{l}\text { Patients } \\
\text { with } \geq \mathbf{5 0 \%} \\
\text { improvement }\end{array}$ \\
\hline Magis et al. [47, 103, 107] & 15 & 36.8 & 11 \\
Burns et al. [108, 109] & 14 & 17.5 & 5 \\
De Quintana et al. [110] & 4 & 6 & 4 \\
Mueller et al. [114] & 10 & 12 & 9 \\
Mueller et al. [104] & 24 & 20 & 21 \\
Fontaine et al. [111] & 13 & 14.6 & 10 \\
Strand et al. [112] & 3 & 12 & 2 \\
Leone et al. [113] & 35 & 72 & 20 \\
Miller et al. [106] & 51 & 39.17 & 27 \\
Leplus et al. [105] & 93 & 43.8 & 64 \\
TOTAL & 262 & 39.1 & $173(66 \%)$ \\
\hline
\end{tabular}

ONS might suggest a placebo effect, the sudden and marked improvement of symptoms after ONS following a highly stable initial observation period of 12 weeks in patients with a clear long history of highly drug-resistant $\mathrm{CCH}$ supports a strong therapeutic effect of ONS, even at low dosages.

Overall, despite possible adverse events (empty battery, local infection, lead migration, local pain, neck stiffness, or hardware dysfunction), ONS is safer than DBS and SPG stimulation, and the observed frequency improvement is of a similar order to that of DBS.

\section{Conclusions}

After the initial test of risky, invasive neuromodulation procedures, devices allowing non-invasive riskless neurostimulation are becoming more popular, and patients are more willing to try one of these devices than common drug treatments, including monoclonal antibodies against calcitonin gene-related peptide [123].

In short, DBS of the infero-posterior hypothalamus or ventral tegmental area is effective in $\mathrm{CCH}$ (but not without risk); therefore, it should only be reserved for patients who are extremely disabled and extremely difficult to treat. Percutaneous ONS has shown similar efficacy to DBS but with less risk to the patient; it is more effective in SUNCT than other TACs and even CM at a lower intensity. SPG stimulation can abort $\mathrm{CH}$ attacks and can also be effective in reducing their frequency. Transcutaneous cervical eVN stimulation can abort episodic but not chronic $\mathrm{CH}$ attacks and reduce their frequency. Transcutaneous eTN stimulation is also able to abort migraine attacks and may be effective in treating $\mathrm{CM}$ but has not yet been tested in $\mathrm{CCH}$. In favour of using one of these devices is the efficacy rate, often in the range of many drug treatments, and this applies much more to prophylactic therapies than to acute treatment of the attack. In addition, tolerance was generally excellent, with no major treatment-related adverse events. However, their mechanism of action is often elusive, and their cost may discourage their use.

TMS and tDCS may have a preventive effect in both migraine and $\mathrm{CCH}$; however, longer trials are mandatory and require more standardised protocols. We hope that with the advent of new guidelines for clinical trials of neuromodulation devices [124], a higher level of scientific rigor and more solid evidence of the efficacy of this type of non-drug approach will be achieved.

Nevertheless, in the next few years, we will certainly see other devices coming onto the market or being tested not only for episodic headaches but also for CDHs. Examples include transcutaneous extracephalic electrical stimulators [125], caloric vestibular stimulators [126], and percutaneous mastoid electrical stimulators [127]. 
In conclusion, a better understanding of the mechanisms underlying the recurrence of headache attacks, both migraine and $\mathrm{CHs}$, as well as an improved understanding of the mechanisms that favour the transformation of episodic headache into $\mathrm{CDH}$ will contribute to the development of new and more target-specific devices that could relieve pain and its accompanying symptoms.

\section{Compliance with Ethical Standards}

Conflict of Interest G. C., F. C., G. S., C. A., E. C. C. D. L., and M. S. declare no conflict of interest related to the topic of the present manuscript. D. M. received research and travel grants from ElectroCore. She contributed to the study with the supraorbital device Cefaly Technology without any compensation. She took place to several advisory boards organised by Medtronic without any compensation. She kindly received support for training from Theranica Bio-Electronics Ltd without any compensation.

Human and Animal Rights and Informed Consent This article does not contain any studies with human or animal subjects performed by any of the authors.

Open Access This article is licensed under a Creative Commons Attribution 4.0 International License, which permits use, sharing, adaptation, distribution and reproduction in any medium or format, as long as you give appropriate credit to the original author(s) and the source, provide a link to the Creative Commons licence, and indicate if changes were made. The images or other third party material in this article are included in the article's Creative Commons licence, unless indicated otherwise in a credit line to the material. If material is not included in the article's Creative Commons licence and your intended use is not permitted by statutory regulation or exceeds the permitted use, you will need to obtain permission directly from the copyright holder. To view a copy of this licence, visit http://creativecommons.org/licenses/by/4.0/.

\section{References}

Papers of particular interest, published recently, have been highlighted as:

- Of importance

$\bullet$ Of major importance

1. Cameron C, Kelly S, Hsieh SC, Murphy M, Chen L, Kotb A, et al. Triptans in the acute treatment of migraine: a systematic review and network meta-analysis. Headache. 2015;55(Suppl 4):221-35.

2. Thorlund K, Toor K, Wu P, Chan K, Druyts E, Ramos E, et al. Comparative tolerability of treatments for acute migraine: a network meta-analysis. Cephalalgia. 2017;37:965-78.

3. Hepp Z, Dodick DW, Varon SF, Chia J, Matthew N, Gillard P, et al. Persistence and switching patterns of oral migraine prophylactic medications among patients with chronic migraine: a retrospective claims analysis. Cephalalgia. 2017;37:470-85.

4. Silberstein SD. Preventive migraine treatment. Continuum (Minneap Minn). 2015;21:973-89.
5. Turner DP, Golding AN, Houle TT. Using a graphical risk tool to examine willingness to take migraine prophylactic medications. Pain. 2016;157:2226-34.

6. Tso AR, Goadsby PJ. Anti-CGRP monoclonal antibodies: the next era of migraine prevention? Curr Treat Options Neurol. 2017;19:27.

7. Andreou AP, Holland PR, Akerman S, Summ O, Fredrick J, Goadsby PJ. Transcranial magnetic stimulation and potential cortical and trigeminothalamic mechanisms in migraine. Brain. 2016;139:2002-14.

8. Bohotin V, Fumal A, Vandenheede M, Gérard P, Bohotin C, de Noordhout A, et al. Effects of repetitive transcranial magnetic stimulation on visual evoked potentials in migraine. Brain. 2002;125:912-22.

9. Coppola G, De Pasqua V, Pierelli F, Schoenen J. Effects of repetitive transcranial magnetic stimulation on somatosensory evoked potentials and high frequency oscillations in migraine. Cephalalgia. 2012;32:700-9.

10. Kalita J, Bhoi SK, Misra UK. Effect of high rate rTMS on somatosensory evoked potential in migraine. Cephalalgia. 2017;37:1222-30.

11. Clarke B, Upton AR, Kamath MV, Al-Harbi T, Castellanos CM. Transcranial magnetic stimulation for migraine: clinical effects. J Headache Pain. 2006;7:341-6.

12. Bhola R, Kinsella E, Giffin N, Lipscombe S, Ahmed F, Weatherall M, et al. Single-pulse transcranial magnetic stimulation (sTMS) for the acute treatment of migraine: evaluation of outcome data for the UK post market pilot program. J Headache Pain. 2015;16:535.

13. Starling AJ, Tepper SJ, Marmura MJ, Shamim EA, Robbins MS, Hindiyeh N, et al. A multicenter, prospective, single arm, open label, observational study of sTMS for migraine prevention (ESPOUSE Study). Cephalalgia. 2018;38:1038-48.

14. Brighina F, Piazza A, Vitello G, Aloisio A, Palermo A, Daniele $\mathrm{O}$, et al. rTMS of the prefrontal cortex in the treatment of chronic migraine: a pilot study. J Neurol Sci. 2004;227:67-71.

15. Misra UK, Kalita J, Bhoi SK. High frequency repetitive transcranial magnetic stimulation (rTMS) is effective in migraine prophylaxis: an open labeled study. Neurol Res. 2012;34:547-51.

16. Misra UK, Kalita J, Bhoi SK. High-rate repetitive transcranial magnetic stimulation in migraine prophylaxis: a randomized, placebo-controlled study. J Neurol. 2013;260:2793-801.

17. Kalita J, Laskar S, Bhoi SK, Misra UK. Efficacy of single versus three sessions of high rate repetitive transcranial magnetic stimulation in chronic migraine and tension-type headache. J Neurol. 2016;263:2238-46.

18. Shehata HS, Esmail EH, Abdelalim A, El-Jaafary S, Elmazny A, Sabbah A, et al. Repetitive transcranial magnetic stimulation versus botulinum toxin injection in chronic migraine prophylaxis: a pilot randomized trial. J Pain Res. 2016;9:771-7.

19. Granato A, Fantini J, Monti F, Furlanis G, Musho Ilbeh S, Semenic M, et al. Dramatic placebo effect of high frequency repetitive TMS in treatment of chronic migraine and medication overuse headache. J Clin Neurosci. 2019;60:96-100.

20. Kumar A, Mattoo B, Bhatia R, Kumaran S, Bhatia R. Neuronavigation based 10 sessions of repetitive transcranial magnetic stimulation therapy in chronic migraine: an exploratory study. Neurol Sci. 2021;42:131-9.

21. Teepker M, Hötzel J, Timmesfeld N, Reis J, Mylius V, Haag A, et al. Low-frequency rTMS of the vertex in the prophylactic treatment of migraine. Cephalalgia. 2010;30:137-44.

22. Conforto AB, Amaro E, Gonçalves AL, Mercante JP, Guendler VZ, Ferreira JR, et al. Randomized, proof-of-principle clinical trial of active transcranial magnetic stimulation in chronic migraine. Cephalalgia. 2014;34:464-72.

23. Teo W-P, Kannan A, Loh P-K, Chew E, Sharma VK, Chan Y-C. Poor tolerance of motor cortex rTMS in chronic migraine. J Clin Diagn Res. 2014;8:MM01-2. 
24. Rapinesi C, Del Casale A, Scatena P, Kotzalidis GD, Di Pietro S, Ferri VR, et al. Add-on deep transcranial magnetic stimulation (dTMS) for the treatment of chronic migraine: a preliminary study. Neurosci Lett. 2016;623:7-12.

25. Hodaj H, Alibeu J-P, Payen J-F, Lefaucheur J-P. Treatment of chronic facial pain including cluster headache by repetitive transcranial magnetic stimulation of the motor cortex with maintenance sessions: a naturalistic study. Brain Stimul. 2015;8:801-7.

26. Chen PR, Lai KL, Fuh JL, Chen SP, Wang PN, Liao KK, et al. Efficacy of continuous theta burst stimulation of the primary motor cortex in reducing migraine frequency: a preliminary open-label study. J Chin Med Assoc. 2016;79:304-8.

27. Siniatchkin M, Sendacki M, Moeller F, Wolff S, Jansen O, Siebner H, et al. Abnormal changes of synaptic excitability in migraine with aura. Cereb cortex. 2012;22:2207-16.

28. Vecchio E, Ricci K, Montemurno A, Delussi M, Invitto S, de Tommaso M. Effects of left primary motor and dorsolateral prefrontal cortex transcranial direct current stimulation on laserevoked potentials in migraine patients and normal subjects. Neurosci Lett. 2016;626:149-57.

29. Cortese F, Pierelli F, Bove I, Di Lorenzo C, Evangelista M, Perrotta A, et al. Anodal transcranial direct current stimulation over the left temporal pole restores normal visual evoked potential habituation in interictal migraineurs. J Headache Pain. 2017;18:70.

30. Polanía R, Paulus W, Nitsche MA. Modulating cortico-striatal and thalamo-cortical functional connectivity with transcranial direct current stimulation. Hum Brain Mapp. 2012;33:2499-508.

31. Fumal A, Laureys S, Di Clemente L, Boly M, Bohotin V, Vandenheede $\mathrm{M}$, et al. Orbitofrontal cortex involvement in chronic analgesic-overuse headache evolving from episodic migraine. Brain. 2006;129:543-50.

32. Noseda R, Kainz V, Jakubowski M, Gooley JJ, Saper CB, Digre $\mathrm{K}$, et al. A neural mechanism for exacerbation of headache by light. Nat Neurosci. 2010;13:239-45.

33. Burstein R, Jakubowski M, Garcia-Nicas E, Kainz V, Bajwa Z, Hargreaves R, et al. Thalamic sensitization transforms localized pain into widespread allodynia. Ann Neurol. 2010;68:81-91.

34. Porcaro C, Di Lorenzo G, Seri S, Pierelli F, Tecchio F, Coppola G. Impaired brainstem and thalamic high-frequency oscillatory EEG activity in migraine between attacks. Cephalalgia. 2017;37:915-26.

35. Mencarelli L, Menardi A, Neri F, Monti L, Ruffini G, Salvador $\mathrm{R}$, et al. Impact of network-targeted multichannel transcranial direct current stimulation on intrinsic and network-to-network functional connectivity. J Neurosci Res. 2020;98:1843-56.

36. Coppola G, Parisi V, Di Renzo A, Pierelli F. Cortical pain processing in migraine. J Neural Transm. 2020;127:551-66.

37. Antal A, Kriener N, Lang N, Boros K, Paulus W. Cathodal transcranial direct current stimulation of the visual cortex in the prophylactic treatment of migraine. Cephalalgia. 2011;31:820-8.

38. Rocha S, Melo L, Boudoux C, Foerster Á, Araújo D, MonteSilva K. Transcranial direct current stimulation in the prophylactic treatment of migraine based on interictal visual cortex excitability abnormalities: a pilot randomized controlled trial. J Neurol Sci. 2015;349:33-9.

39. Dasilva A, Mendonca ME, Zaghi S, Lopes M, Dossantos MF, Spierings EL, et al. tDCS-induced analgesia and electrical fields in pain-related neural networks in chronic migraine. Headache. 2012;52:1283-95.

40. Auvichayapat P, Janyacharoen T, Rotenberg A, Tiamkao S, Krisanaprakornkit T, Sinawat S, et al. Migraine prophylaxis by anodal transcranial direct current stimulation, a randomized, placebo-controlled trial. J Med Assoc Thai. 2012;95:1003-12.

41. Przeklasa-Muszyńska A, Kocot-Kępska M, Dobrogowski J, Wiatr M, Mika J. Transcranial direct current stimulation (tDCS) and its influence on analgesics effectiveness in patients suffering from migraine headache. Pharmacol Reports. 2017;69:714-21.
42. Andrade SM, de Brito Aranha REL, de Oliveira EA, de Mendonça CTPL, Martins WKN, Alves NT, et al. Transcranial direct current stimulation over the primary motor vs prefrontal cortex in refractory chronic migraine: a pilot randomized controlled trial. J Neurol Sci. 2017;378:225-32.

43. Rahimi MD, Fadardi JS, Saeidi M, Bigdeli I, Kashiri R. Effectiveness of cathodal tDCS of the primary motor or sensory cortex in migraine: a randomized controlled trial. Brain Stimul. 2020;13:675-82.

44. Mansour AG, Ahdab R, Khazen G, El-Khoury C, Sabbouh TM, Salem M, et al. Transcranial direct current stimulation of the occipital cortex in medication overuse headache: a pilot randomized controlled cross-over study. J Clin Med. 2020;9:1075.

45. Grazzi L, Usai S, Bolognini N, Grignani E, Sansone E, Tramacere I, et al. No efficacy of transcranial direct current stimulation on chronic migraine with medication overuse: a double blind, randomised clinical trial. Cephalalgia. 2020;40:1202-11.

46. Yoon EJ, Kim YK, Kim H-R, Kim SE, Lee Y, Shin HI. Transcranial direct current stimulation to lessen neuropathic pain after spinal cord injury: a mechanistic PET study. Neurorehabil Neural Repair Neurorehabil Neural Repair. 2014;28:250-9.

47. Magis D, Bruno MA, Fumal A, Gérardy PY, Hustinx R, Laureys $\mathrm{S}$, et al. Central modulation in cluster headache patients treated with occipital nerve stimulation: an FDG-PET study. BMC Neurol. 2011;11:25.

48.•• Magis D, D’Ostilio K, Lisicki M, Lee C, Schoenen J. Anodal frontal tDCS for chronic cluster headache treatment: a proof-ofconcept trial targeting the anterior cingulate cortex and searching for nociceptive correlates. J Headache Pain. 2018;19. Unique open trial using tDCS in $\mathrm{rCCH}$.

49. Brittain J-S, Green AL, Jenkinson N, Ray NJ, Holland P, Stein $\mathrm{JF}$, et al. Local field potentials reveal a distinctive neural signature of cluster headache in the hypothalamus. Cephalalgia. 2009;29:1165-73.

50. Schoenen J. Migraine treatment with external trigeminal nerve stimulation: current knowledge on mechanisms. Intern Med Rev. 2017;3:1-17.

51. Piquet M, Balestra C, Sava SL, Schoenen JE. Supraorbital transcutaneous neurostimulation has sedative effects in healthy subjects. BMC Neurol. 2011;11:135.

52. Magis D, D’Ostilio K, Thibaut A, De Pasqua V, Gerard P, Hustinx R, et al. Cerebral metabolism before and after external trigeminal nerve stimulation in episodic migraine. Cephalalgia. 2017;37:881-91.

53. Russo A, Tessitore A, Esposito F, Di Nardo F, Silvestro M, Trojsi $\mathrm{F}$, et al. Functional changes of the perigenual part of the anterior cingulate cortex after external trigeminal neurostimulation in migraine patients. Front Neurol. 2017;8:282.

54. Di Lenola D, Coppola G, Serrao M, Di Lorenzo C, Pierelli F. O024. Transcutaneous supraorbital nerve stimulation enhances somatosensory thalamic activity in migraine between attacks: a central mechanism of clinical efficacy? J Headache Pain. 2015; 16.

55. Schoenen J, Vandersmissen B, Jeangette S, Herroelen L, Vandenheede M, Gérard P, et al. Migraine prevention with a supraorbital transcutaneous stimulator: a randomized controlled trial. Neurology. 2013;80:697-704.

56. Birlea M, Penning S, Callahan K, Schoenen J. Efficacy and safety of external trigeminal neurostimulation in the prevention of chronic migraine: an open-label trial. Cephalalgia Reports. 2019. https://doi.org/10.1177/2515816319856625.

57.• Vikelis M, Dermitzakis EV, Spingos KC, Vasiliadis GG, Vlachos GS, Kararizou E. Clinical experience with transcutaneous supraorbital nerve stimulation in patients with refractory migraine or with migraine and intolerance to topiramate: a prospective exploratory clinical study. BMC Neurol. 2017;17:97. This open trial shows that eTN is able to 
reduce headache frequency equally in episodic and chronic migraine.

58. Danno D, Iigaya M, Imai N, Igarashi H, Takeshima T. The safety and preventive effects of a supraorbital transcutaneous stimulator in Japanese migraine patients. Sci Rep. 2019;9.

59. Frangos E, Komisaruk BR. Access to vagal projections via cutaneous electrical stimulation of the neck: fMRI evidence in healthy humans. Brain Stimul. 2017;10:19-27.

60. Frangos E, Ellrich J, Komisaruk BR. Non-invasive access to the vagus nerve central projections via electrical stimulation of the external ear: fMRI evidence in humans. Brain Stimul. 2015;8:624-36.

61. Chen SP, Ay I, De Morais AL, Qin T, Zheng Y, Sadeghian $\mathrm{H}$, et al. Vagus nerve stimulation inhibits cortical spreading depression. Pain. 2016;157:797-805.

62. Morais A, Liu TT, Qin T, Sadhegian H, Ay I, Yagmur D, et al. Vagus nerve stimulation inhibits cortical spreading depression exclusively through central mechanisms. Pain. 2020;161:1661-9.

63. Hawkins JL, Cornelison LE, Blankenship BA, Durham PL. Vagus nerve stimulation inhibits trigeminal nociception in a rodent model of episodic migraine. Pain Rep. 2017;2.

64. Cornelison LE, Woodman SE, Durham PL. Inhibition of trigeminal nociception by non-invasive vagus nerve stimulation: investigating the role of GABAergic and serotonergic pathways in a model of episodic migraine. Front Neurol. 2020;11:146.

65. Cornelison LE, Hawkins JL, Woodman SE, Durham PL. Noninvasive vagus nerve stimulation and morphine transiently inhibit trigeminal pain signaling in a chronic headache model. Pain Rep. 2020;5:e881.

66. Lerman I, Davis B, Huang M, Huang C, Sorkin L, Proudfoot J, et al. Noninvasive vagus nerve stimulation alters neural response and physiological autonomic tone to noxious thermal challenge. PLoS One. 2019;14:e201212.

67. Möller M, Schroeder CF, May A. Vagus nerve stimulation modulates the cranial trigeminal autonomic reflex. Ann Neurol. 2018;84:886-92.

68. Schroeder CF, Möller M, May A. NVNS sham significantly affects the trigeminal-autonomic reflex: a randomized controlled study. Neurology. 2019;93:E518-21.

69. Möller M, Mehnert J, Schroeder CF, May A. Noninvasive vagus nerve stimulation and the trigeminal autonomic reflex: an fMRI study. Neurology. 2020;94:e1085-93.

70. Silberstein SD, Calhoun AH, Lipton RB, Grosberg BM, Cady RK, Dorlas S, et al. Chronic migraine headache prevention with noninvasive vagus nerve stimulation. Neurology. 2016;87:529-38.

71. Chaudhry SR, Lendvai IS, Muhammad S, Westhofen P, Kruppenbacher J, Scheef L, et al. Inter-ictal assay of peripheral circulating inflammatory mediators in migraine patients under adjunctive cervical non-invasive vagus nerve stimulation (nVNS): A proof-of-concept study. Brain Stimul. 2019;12:643-51.

72. Kinfe TM, Pintea B, Muhammad S, Zaremba S, Roeske S, Simon BJ, et al. Cervical non-invasive vagus nerve stimulation (nVNS) for preventive and acute treatment of episodic and chronic migraine and migraine-associated sleep disturbance: preliminary findings from a prospective observational cohort study. J Headache Pain. 2015;16:1-11.

73. Trimboli M, Al-Kaisy A, Andreou AP, Murphy M, Lambru G. Noninvasive vagus nerve stimulation for the management of refractory primary chronic headaches: a real-world experience. Cephalalgia. 2018;38:1276-85. Real-world data do not confirm the efficacy of eTN in the treatment of chronic migraine.

74. Gaul C, Diener HC, Silver N, Magis D, Reuter U, Andersson A, et al. Non-invasive vagus nerve stimulation for PREVention and Acute treatment of chronic cluster headache (PREVA): a randomised controlled study. Cephalalgia. 2016;36:534-46.
75. Marin J, Giffin N, Consiglio E, McClure C, Liebler E, Davies B. Non-invasive vagus nerve stimulation for treatment of cluster headache: early UK clinical experience 11 Medical and Health Sciences 1103 Clinical Sciences. J Headache Pain. 2018;19:1-6.

76. de Coo IF, Marin JCA, Silberstein SD, Friedman DI, Gaul C, McClure CK, et al. Differential efficacy of non-invasive vagus nerve stimulation for the acute treatment of episodic and chronic cluster headache: a meta-analysis. Cephalalgia. 2019;39:967-77.

77. May A, Bahra A, Büchel C, Frackowiak RS, Goadsby PJ. Hypothalamic activation in cluster headache attacks. Lancet. 1998;352:275-8.

78. Leone M, Franzini A, Bussone G. Stereotactic stimulation of posterior hypothalamic gray matter in a patient with intractable cluster headache. N Engl J Med. 2001;345:1428-9.

79. Leone M, Franzini A, Felisati G, Mea E, Curone M, Tullo V, et al. Deep brain stimulation and cluster headache. Neurol Sci. 2005;26(Suppl 2):s138-9.

80. Sprenger T, Ruether KV, Boecker H, Valet M, Berthele A, Pfaffenrath V, et al. Altered metabolism in frontal brain circuits in cluster headache. Cephalalgia. 2007;27:1033-42.

81. Sánchez Del Rio M, Alvarez LJ. Functional neuroimaging of headaches. Lancet Neurol. 2004;3:645-51.

82. Matharu MS, Zrinzo L. Deep brain stimulation in cluster headache: hypothalamus or midbrain tegmentum? Curr Pain Headache Rep. 2010;14:151-9.

83. Leone M, Proietti CA. Deep brain stimulation in headache. Cephalalgia. 2016;36:1143-8.

84. Lantéri-Minet M, Fontaine D, Magis D. Neurostimulation: why, when, and which one? In: Cluster headache and other trigeminal autonomic cephalgias. Eds Leone M, May A; Springer Nature, Switzerland; 2020;153-67.

85. Fontaine D, Lazorthes Y, Mertens P, Blond S, Géraud G, Fabre $\mathrm{N}$, et al. Safety and efficacy of deep brain stimulation in refractory cluster headache: a randomized placebo-controlled doubleblind trial followed by a 1-year open extension. J Headache Pain. 2010;11:23-31.

86. Leone M, Franzini A, Proietti Cecchini A, Bussone G. Success, failure, and putative mechanisms in hypothalamic stimulation for drug-resistant chronic cluster headache. Pain. 2013;154:89-94.

87. Leone M, Franzini A, Broggi G, Mea E, Cecchini AP, Bussone G. Acute hypothalamic stimulation and ongoing cluster headache attacks. Neurology. 2006;67:1844-5.

88. Bartsch T, Falk D, Knudsen K, Reese R, Raethjen J, Mehdorn $\mathrm{HM}$, et al. Deep brain stimulation of the posterior hypothalamic area in intractable short-lasting unilateral neuralgiform headache with conjunctival injection and tearing (SUNCT). Cephalalgia. 2011;31:1405-8.

89. Leone M, Franzini A, D’Andrea G, Broggi G, Casucci G, Bussone G. Deep brain stimulation to relieve drug-resistant SUNCT. Ann Neurol. 2005;57:924-7.

90. Lyons MK, Dodick DW, Evidente VGH. Responsiveness of short-lasting unilateral neuralgiform headache with conjunctival injection and tearing to hypothalamic deep brain stimulation. J Neurosurg. 2009;110:279-81.

91. Walcott BP, Bamber NI, Anderson DE. Successful treatment of chronic paroxysmal hemicrania with posterior hypothalamic stimulation: technical case report. Neurosurgery. 2009;65:E997.

92. Cappon D, Ryterska A, Lagrata S, Miller S, Akram H, Hyam J, et al. Ventral tegmental area deep brain stimulation for chronic cluster headache: effects on cognition, mood, pain report behaviour and quality of life. Cephalalgia. 2019;39:1099-110.

93. Akram H, Miller S, Lagrata S, Hyam J, Jahanshahi M, Hariz M, et al. Ventral tegmental area deep brain stimulation for refractory chronic cluster headache. Neurology. 2016;86:1676-82.

94. Cappon D, Ryterska A, Akram H, Lagrata S, Cheema S, Hyam $\mathrm{J}$, et al. The sensitivity to change of the cluster headache quality 
of life scale assessed before and after deep brain stimulation of the ventral tegmental area. J Headache Pain. 2021;22.

95. Evidente VGH, Ponce FA, Evidente MH, Garrett R, Lambert M. Short-lasting unilateral neuralgiform headache with conjunctival injection and tearing (SUNCT) improves with bilateral ventral tegmental area deep brain stimulation. Headache. 2020;60:2548-54.

96. Miller S, Akram H, Lagrata S, Hariz M, Zrinzo L, Matharu $\mathrm{M}$. Ventral tegmental area deep brain stimulation in refractory short-lasting unilateral neuralgiform headache attacks. Brain. 2016;139:2631-40.

97. Schoenen J, Di Clemente L, Vandenheede M, Fumal A, De Pasqua V, Mouchamps M, et al. Hypothalamic stimulation in chronic cluster headache: a pilot study of efficacy and mode of action. Brain. 2005;128:940-7.

98. May A, Schwedt TJ, Magis D, Pozo-Rosich P, Evers S, Wang SJ. Cluster headache. Nat Rev Dis Prim. 2018;4:18006.

99. Schoenen J, Jensen RH, Lantéri-Minet M, Láinez MJ, Gaul C, Goodman AM, et al. Stimulation of the sphenopalatine ganglion (SPG) for cluster headache treatment. Pathway $\mathrm{CH}-1$ : A randomized, sham-controlled study. Cephalalgia. 2013;33:816-30.

100. Jürgens TP, Barloese M, May A, Láinez JM, Schoenen J, Gaul $\mathrm{C}$, et al. Long-term effectiveness of sphenopalatine ganglion stimulation for cluster headache. Cephalalgia. 2017;37:423-34.

101. Barloese M, Petersen A, Stude P, Jürgens T, Jensen RH, May A. Sphenopalatine ganglion stimulation for cluster headache, results from a large, open-label European registry. J Headache Pain. 2018;19.

102. García-Magro N, Negredo P, Martin YB, Nuñez Á, Avendaño C. Modulation of mechanosensory vibrissal responses in the trigeminocervical complex by stimulation of the greater occipital nerve in a rat model of trigeminal neuropathic pain. J Headache Pain. 2020;21.

103. Magis D, Allena M, Bolla M, De Pasqua V, Remacle J-M, Schoenen J. Occipital nerve stimulation for drug-resistant chronic cluster headache: a prospective pilot study. Lancet Neurol. 2007;6:314-21.

104. Mueller O, Diener HC, Dammann P, Rabe K, Hagel V, Sure U, et al. Occipital nerve stimulation for intractable chronic cluster headache or migraine: a critical analysis of direct treatment costs and complications. Cephalalgia. 2013;33:1283-91.

105. Leplus A, Fontaine D, Donnet A, Regis J, Lucas C, Buisset N, et al. Long-term efficacy of occipital nerve stimulation for medically intractable cluster headache. Neurosurgery. 2021;88:375-83.

106. Miller S, Watkins L, Matharu M. Treatment of intractable chronic cluster headache by occipital nerve stimulation: a cohort of 51 patients. Eur J Neurol. 2017;24:381-90.

107. Magis D, Gerardy PY, Remacle JM, Schoenen J. Sustained effectiveness of occipital nerve stimulation in drug-resistant chronic cluster headache. Headache. 2011;51:1191-201.

108. Burns B, Watkins L, Goadsby PJ. Treatment of medically intractable cluster headache by occipital nerve stimulation: long-term follow-up of eight patients. Lancet. 2007;369:1099-106.

109. Burns B, Watkins L, Goadsby PJ. Treatment of intractable chronic cluster headache by occipital nerve stimulation in 14 patients. Neurology. 2009;72:341-5.

110. De Quintana-Schmidt C, Casajuana-Garreta E, Molet-Teixidó J, García-Bach M, Roig C, Clavel-Laria P, et al. Stimulation of the occipital nerve in the treatment of drug-resistant cluster headache. Rev Neurol. 2010;51:19-26.

111. Fontaine D, Christophe Sol J, Raoul S, Fabre N, Geraud G, Magne $\mathrm{C}$, et al. Treatment of refractory chronic cluster headache by chronic occipital nerve stimulation. Cephalalgia. 2011;31:1101-5.

112. Strand N, Trentman T, Vargas B, Dodick D. Occipital nerve stimulation with the Bion ${ }^{\circledR}$ microstimulator for the treatment of medically refractory chronic cluster headache. Pain Physician. 2011;14:435-40.
113. Leone M, Proietti Cecchini A, Messina G, Franzini A. Longterm occipital nerve stimulation for drug-resistant chronic cluster headache. Cephalalgia. 2017;37:756-63.

114. Mueller OM, Gaul C, Katsarava Z, Diener HC, Sure U, Gasser T. Occipital nerve stimulation for the treatment of chronic cluster headache - lessons learned from 18 months experience. Cent Eur Neurosurg. 2011;72:84-9.

115. Miller S, Watkins L, Matharu M. Long-term outcomes of occipital nerve stimulation for chronic migraine: a cohort of 53 patients. J Headache Pain. 2016;17.

116. Burns B, Watkins L, Goadsby PJ. Treatment of hemicrania continua by occipital nerve stimulation with a bion device: long-term follow-up of a crossover study. Lancet Neurol. 2008;7:1001-12.

117. Miller S, Watkins L, Matharu MS. Treatment of intractable hemicrania continua by occipital nerve stimulation. J Neurol Neurosurg Psychiatry. 2017;88:805-6.

118. Miller S, Lagrata S, Watkins L, Matharu M. Occipital nerve stimulation for medically refractory chronic paroxysmal hemicrania. Headache. 2017;57:1610-3.

119. Matharu M, Lambru G, Shanahan P, Watkins L. Occipital nerve stimulation in the treatment of medically intractable SUNCT and SUNA. Pain Physician. 2014;17:29-41.

120. Miller S, Watkins L, Matharu M. Long-term follow up of intractable chronic short lasting unilateral neuralgiform headache disorders treated with occipital nerve stimulation. Cephalalgia. 2018;38:933-42.

121. Miller S, Watkins L, Matharu M. Predictors of response to occipital nerve stimulation in refractory chronic headache. Cephalalgia. 2018;38:1267-75. This study helps to understand which factors are predictive of positive or negative response to ONS treatment in $\mathbf{r C C H}$.

122.• Wilbrink LA, de Coo IF, Doesborg PGG, Mulleners WM, Teernstra OPM, Bartels EC, et al. Safety and efficacy of occipital nerve stimulation for attack prevention in medically intractable chronic cluster headache (ICON): a randomised, double-blind, multicentre, phase 3, electrical dose-controlled trial. Lancet Neurol. 2021;20:515-25. Unique international, multicentre, randomised, double-blind, phase 3 trial using ONS in rCCH.

123. Mitsikostas DD, Belesioti I, Arvaniti C, Mitropoulou E, Deligianni C, Kasioti E, et al. Patients' preferences for headache acute and preventive treatment. J Headache Pain. 2017;18.

124. Tassorelli C, Diener HC, Silberstein SD, Dodick DW, Goadsby $\mathrm{PJ}$, Jensen RH, et al. Guidelines of the International Headache Society for clinical trials with neuromodulation devices for the treatment of migraine. Cephalalgia. 2021;41:1135-51.

125. Yarnitsky D, Volokh L, Ironi A, Weller B, Shor M, Shifrin A, et al. Nonpainful remote electrical stimulation alleviates episodic migraine pain. Neurology. 2017;88:1250-5.

126. Wilkinson D, Ade KK, Rogers LL, Attix DK, Kuchibhatla M, Slade MD, et al. Preventing episodic migraine with caloric vestibular stimulation: a randomized controlled trial. Headache. 2017;57:1065-87.

127. Juan Y, Shu O, Jinhe L, Na Y, Yushuang D, Weiwei D, et al. Migraine prevention with percutaneous mastoid electrical stimulator: a randomized double-blind controlled trial. Cephalalgia. 2017;37:1248-56.

128. Dalla Volta G, Marceglia S, Zavarise P, Antonaci F. Cathodal tDCS guided by thermography as adjunctive therapy in chronic migraine patients: a sham-controlled pilot study. Front Neurol. $2020 ; 11$.

Publisher's Note Springer Nature remains neutral with regard to jurisdictional claims in published maps and institutional affiliations. 